Article

\title{
Effects of Dark Brown Sugar Replacing Sucrose and Calcium Carbonate, Chitosan, and Chitooligosaccharide Addition on Acrylamide and 5-Hydroxymethylfurfural Mitigation in Brown Sugar Cookies
}

\author{
Yung-Shin Shyu ${ }^{1}$, Hsin-I Hsiao ${ }^{2}$, Jui-Yu Fang ${ }^{2}$ and Wen-Chieh Sung ${ }^{2,3, *(D)}$ \\ 1 Department of Baking Technology and Management, National Kaohsiung University of Hospitality and \\ Tourism, No.1, Songhe Rd., Xiaogang Dist., Kaohsiung City 81271, Taiwan; tristar@mail.nkuht.edu.tw \\ 2 Department of Food Science, National Taiwan Ocean University, Keelung 20224, Taiwan; \\ hi.hsiao@mail.ntou.edu.tw (H.-I.H.); f89250013@yahoo.com.tw (J.-Y.F.) \\ 3 Center of Excellence for the Oceans, National Taiwan Ocean University, Keelung 20224, Taiwan \\ * Correspondence: sungwill@mail.ntou.edu.tw; Tel.: +11-8862-24622192 (ext. 5129)
}

Received: 29 April 2019; Accepted: 5 June 2019; Published: 10 June 2019

check for updates

\begin{abstract}
The objective of this study was to evaluate effects of dark brown sugar on acrylamide and 5-hydroxymethylfurfural (HMF) levels in brown sugar cookies. Dark brown sugar was used as a raw material instead of sucrose, and chitosan, chitooligosaccharides, or calcium carbonate were added to investigate their effect on acrylamide and HMF mitigation. The results demonstrated that the higher the content of acrylamide in the dark brown sugar, the higher the amount of acrylamide produced in baked brown sugar cookies. The addition of dark brown sugar significantly increased the diameter and decreased the thickness of cookies, which induced more acrylamide formation. Therefore, the sucrose control cookies were harder and thicker than dark brown sugar cookies. The addition of $1 \%$ chitosan, chitooligosaccharide, or calcium carbonate did not reduce the acrylamide formation of the brown sugar cookies. The content of acrylamide and HMF in the sucrose control group was lower than that in dark brown sugar groups, and chitooligosaccharide increased the level of HMF. This is due to the fact that the content of reducing sugar in dark brown sugar is higher than that in sucrose, and dark brown sugar contains acrylamide. There was no difference in the concentration of reducing sugar between test and control cookies $(p>0.05)$. The L values of brown sugar were lower than those of sucrose cookies, especially for chitooligosaccharide addition $(p<0.05)$. The addition of chitooligosaccharide generated more Maillard reaction products and caramelization. The reducing power of dark brown sugar cookies was higher than that of sucrose control cookies. The baking industry should choose sucrose or dark brown sugar containing a low acrylamide content as an ingredient to prevent the final products from containing high levels of acrylamide.
\end{abstract}

Keywords: dark brown sugar; brown sugar cookie; acrylamide; 5-hydroxymethylfurfural; chitooligosaccharide

\section{Introduction}

Dark brown sugar is a solidified form of sugar derived from sugar cane juice and has been a popular product in Taiwan and many other countries [1]. It is not used for table sugar; snacks; or as a major ingredient for the production of confectionary, bakery products, and beverages [2]; instead, it is used as a form of souvenir candy or coffee/tea sweetener. Dark brown sugar mainly consists of fructose, glucose, and sucrose along with minor components such as insoluble solids, phenolics, 
proteins, minerals, and natural asparagines, all of which contribute to it biological and nutritional values [3]. During processing, raw sugar cane juice is limed, clarified, and repeatedly evaporated by open pan-drying without removing the molasses components. Its brown appearance and flavor come from the Maillard reaction products, caramelization, and the phenolic compounds in sugar cane juice [4]. Acrylamide and 5-hydroxymethylfurfural (HMF) also form during the process of concentrating dark brown sugar [2]. Acrylamide is a carcinogenic neurotoxic compound formed in heated starchy food [5]. Tareke et al. [6] proposed that food cooked at high temperatures is a major source of acrylamide consumed by humans. In Hong Kong, acrylamide from brown sugar contributes to less than $1 \%$ of the total acrylamide intake of adults $(28-860 \mu \mathrm{g} / \mathrm{kg})$ [2]. The acrylamide content of baked and fried starchy foods can range between 150 and 4,000 $\mu \mathrm{g} / \mathrm{kg}$ [6], and the development of effective ways to reduce the acrylamide content in baked and fried starchy foods is an important issue facing food manufacturers. HMF, which is claimed to have genotoxic and mutagenic effects [7], is formed by caramelization of reducing sugars or by the Maillard reaction in heated foods [8]. Although dark brown sugar is popular in the production of beverage and bakery products in Taiwan, concerns over the high acrylamide content have attracted much attention [9].

Calcium is well known for its ability to prevent osteoporosis, and the calcium ions in heated food products interfere with acrylamide formation [10]. Therefore, fortifying brown sugar cookies with calcium carbonate might mitigate the formation of acrylamide during the baking process. Laboratory experiments have shown that low-molecular-weight chitosan $(50-190 \mathrm{kDa})$ can be used to reduce the acrylamide content in a model system [11,12], although this has not yet been tested at an industrial level.

Several practices have been claimed to inhibit acrylamide formation in heated foods: the addition of divalent cations, such as calcium salts [13,14]; replacement of reducing sugars such as glucose and fructose with nonreducing sugars such as sucrose [15-17]; adding baking powder to replace ammonium salts [18]; adding acidulants to lower the $\mathrm{pH}$ of the food system [19]; lowering asparagine concentration by adding glycine [20]; and reducing free asparagine content with asparaginase [21,22].

Sucrose is the main ingredient used by most baking industries in Taiwan. However, some bakeries prefer using dark brown sugar for special breads, cakes, and cookies because it gives a unique appearance and flavor and is considered to be healthy. However, the effect of adding $1 \%$ calcium carbonate, chitosan, or chitooligosaccharide on acrylamide and HMF mitigation in dark brown sugar cookies has not been evaluated. The objective of this study was to evaluate acrylamide and HMF levels in brown sugar cookies. Dark brown sugar was used as a raw material instead of sucrose, and chitosan, chitooligosaccharides, or calcium carbonate were added to investigate their effect on acrylamide and HMF mitigation.

\section{Materials and Methods}

\subsection{Raw Materials and Chemicals}

The cake flour used in the present experiment was obtained from the Cha Hwa Corporation (Taichung, Taiwan). Food-grade ammonium bicarbonate $\left(\left(\mathrm{NH}_{4}\right) \mathrm{HCO}_{3}\right)$, calcium carbonate $\left(\mathrm{CaCO}_{3}\right)$, sodium bicarbonate $\left(\mathrm{NaHCO}_{3}\right)$, high-fructose $(75 \%)$ corn syrup, skim milk, fat, and sucrose were purchased from a local store (Fu Shen Baking Ingredient Store, Keelung, Taiwan). Dark brown sugar was purchased from the Taiwan Sugar Corporation (Tainan, Taiwan) and Eatplus Corporation (Taipei, Taiwan). Chitooligosaccharide $(1.22 \mathrm{kDa})$ with $90.8 \%$ deacetylation degrees and $<30 \mathrm{kDa}$ chitosan with $85 \%$ deacetylation degrees was obtained from C\&B Co., Ltd. (Taipei, Taiwan), which is derived from the shells of shrimp. D-glucose, ${ }^{13} \mathrm{C}_{3}$-labeled acrylamide, ethanol, ferric chloride $\left(\mathrm{FeCl}_{3}\right)$, hydrochloric acid $(\mathrm{HCl})$, and ferrozine $\left(\mathrm{C}_{20} \mathrm{H}_{13} \mathrm{~N}_{4} \mathrm{NaO}_{6} \mathrm{~S}_{2}\right)$ were purchased from Sigma Aldrich (St. Louis, MO, USA). Sodium hydroxide $(\mathrm{NaOH})$, boric acid, trichloroacetic acid (TCA), ascorbic acid, ethylenediaminetetraacetic acid disodium salt dehydrate (EDTA), sulfuric acid $\left(\mathrm{H}_{2} \mathrm{SO}_{4}\right)$, potassium sodium tartrate $\left(\mathrm{C}_{4} \mathrm{H}_{4} \mathrm{KNaO}_{6}\right)$, 3,5-dinitrosalicyclic acid $\left(\mathrm{C}_{7} \mathrm{H}_{4} \mathrm{~N}_{2} \mathrm{O}_{7}\right)$, and sodium dihydrogen phosphate $\left(\mathrm{NaH}_{2} \mathrm{PO}_{4}\right)$ were supplied by Panreac (Barcelona, Spain). Acrylamide $99.9 \%$ 
was supplied by J. T. Baker (Phillipsburg, NJ, USA). Acetonitrile $\left(\mathrm{CH}_{3} \mathrm{CN}\right)$ and formic acid $\left(\mathrm{HCO}_{2} \mathrm{H}\right)$ were supplied by Merck (Darmstadt, Germany). Oasis HLB (6 mL, $200 \mathrm{mg})$ and Oasis MCX (3 mL, $60 \mathrm{mg}$ ) solid phase extraction (SPE) cartridges were purchased from Waters (Milford, MA, USA).

\subsection{Cookie Preparation and Physicochemical Properties of Brown Sugar Cookies}

For cookie production, the ingredients were: cake flour $(80 \mathrm{~g})$, sucrose $(33.6 \mathrm{~g})$, water $(17.6 \mathrm{~g})$, $0.8 \mathrm{~g}$ nonfat dry milk $(0.8 \mathrm{~g})$, sodium chloride $(\mathrm{NaCl}, 1.0 \mathrm{~g})$, sodium bicarbonate $\left(\mathrm{NaHCO}_{3}, 0.8 \mathrm{~g}\right)$, fat $(32 \mathrm{~g})$, high-fructose syrup $(1.2 \mathrm{~g})$, and ammonium bicarbonate $\left.\left(\left(\mathrm{NH}_{4}\right) \mathrm{HCO}_{3}\right), 0.4 \mathrm{~g}\right)$ following the American Association of Cereal Chemists (AACC) method 10-54 [23]. Dark brown sugars with high and low acrylamide contents (908 and $140 \mathrm{ppb}$, respectively) replaced sucrose in test cookies. The ingredients were mixed for $3 \mathrm{~min}$ in a blender (Oster 6642; Oster, Canton, OH, USA) with a paddle attached. The resulting dough was supplemented with calcium carbonate, chitosan $(<30 \mathrm{kDa})$, or chitooligosaccharide on a dough weight basis of $1 \%$. The spiked and control doughs were all rolled out and cut into discs with a diameter of $65 \mathrm{~mm}$ and a thickness of $2 \mathrm{~mm}$. The disks were baked in an electric oven at $190^{\circ} \mathrm{C}$ for $10 \mathrm{~min}$. The thickness and diameter of the cookies after baking were evaluated following the method of Hwang et al. [24]. The cookie spread ratio was determined by dividing the diameter by the thickness of the cookie. The $\mathrm{pH}$ of the cookies was measured by the method of Navarro and Morales [25].

\subsection{Assay for Reducing Sugars of Brown Sugar Cookies}

A portion $(0.1 \mathrm{~g})$ of ground cookie was added to sulfuric acid $(1.5 \mathrm{M}, 10 \mathrm{~mL})$ and heated for $20 \mathrm{~min}$ in a boiling water bath; $10 \%$ sodium hydroxide $(12 \mathrm{~mL})$ was added after cooling. The mixture was filtered and filled up to $100 \mathrm{~mL}$ with deionized distilled water. A standard glucose solution was prepared for use in the assay for reducing sugars. Reducing sugars were quantified with a standard glucose solution and measured using a dinitrosalicylic-acid-reducing sugar assay following the method of Jame [26].

\subsection{Chromaticity Testing}

Cookie color was determined by using a spectrocolorimeter (TC-1800 MK II, Tokyo, Japan) that measured L value (lightness), a value (redness/greenness), and b value (yellowness/blueness) according the method of Dinc et al. [27].

\subsection{Method for Extracting and Measuring Acrylamide and HMF in Brown Sugar Cookies}

Acrylamide was extracted from the cookies and measured by HPLC following the method of Barber et al. [28]. Cookie samples were ground and a $1 \mathrm{~g}$ sample was put into a $50 \mathrm{~mL}$ centrifuge tube, to which $9 \mathrm{~mL}$ of distilled water was added and then $1 \mathrm{~mL}$ of hexane. The sample was extracted in a reciprocal shaker for $60 \mathrm{~min}$, then the mixture was centrifuged at $1482 \times g\left(4{ }^{\circ} \mathrm{C}\right)$ for $20 \mathrm{~min}$. The supernatant $(3 \mathrm{~mL})$ was filtered through a $0.45 \mu \mathrm{m}$ nylon filter. The HLB/MCX cartridge was conditioned with 5 and $3 \mathrm{~mL}$ of methanol followed by 5 and $3 \mathrm{~mL}$ of deionized distilled water, respectively. The filtrate $(3.0 \mathrm{~mL})$ was passed through the Oasis HLB/MCX cartridge to absorb acrylamide, and then it was discarded. The cartridge was washed with $3.5 \mathrm{~mL}$ of deionized distilled water; the first $0.5 \mathrm{~mL}$ of filtrate was discarded, while the remaining $3.0 \mathrm{~mL}$ of eluent was collected in an amber glass vial. The eluent was concentrated under vacuum for HPLC and MS analysis. HMF levels of brown sugar cookies were also determined using HPLC [29]. Sample preparation was done exactly as described above for acrylamide analysis up to the point of being concentrated under vacuum. The HPLC system (D2000) and column were also the same as in the acrylamide analysis, but the flow rate of the deionized distilled water was faster $(1.0 \mathrm{~mL} / \mathrm{min})$, the mobile phase consisted of acetonitrile, and $20 \mu \mathrm{L}$ of filtered concentrated eluent was injected by autosampler at $10^{\circ} \mathrm{C}$. Standard curves of HMF and acrylamide solution were built in the range of $250-25,000 \mathrm{ng} / \mathrm{mL}$. 
2.6. Extract Preparation for Assays of Antioxidant Activity and 1,1-Diphenyl-2-picrylhydrazyl Hydrate (DPPH) Radical Scavenging

The antioxidant activity of the brown sugar cookies and sucrose control cookies was assayed according to the methods of Kim et al. [30]. Brown sugar cookies were milled and screened through a $0.5 \mathrm{~mm}$ sieve, and $5 \mathrm{~g}$ samples of the sieved crumbs were extracted with $45.0 \mathrm{~mL}$ of methanol using a reciprocal shaker (MS-NOR30, Major Science, CA, USA) at $100 \mathrm{rpm}$ for $24 \mathrm{~h}$. The extracts were centrifuged $(994 \times g)$ at $4{ }^{\circ} \mathrm{C}$ for $20 \mathrm{~min}$. All extracted solutions were filtered and kept in the dark at $-20^{\circ} \mathrm{C}$. The antiradical ability of the methanol extract solution of brown sugar cookies for DPPH was assayed by the method of Shimada et al. [31]. A mixture of $1 \mathrm{~mL}$ of extract solution and 1 $\mathrm{mL}$ of $0.1 \mathrm{mM}$ DPPH $95 \%$ ethanolic solution was kept in the dark for $30 \mathrm{~min}$ at room temperature. The radical-scavenging effect of a sample was expressed as percent disappearance of DPPH, as calculated below:

$$
\text { Scavenging effect }(\%)=\left(1-\left(\mathrm{A}_{517 \text { sample }} / \mathrm{A}_{517 \text { blank }}\right) \times 100 \%\right.
$$

where $A_{517 b l a n k}$ is the absorbance of water plus ethanolic DPPH solution, and $A_{517 s a m p l e}$ is the absorbance of the test sample (DPPH plus extracted solutions) read at $517 \mathrm{~nm}$. A reaction mixture containing ethanolic DPPH solution $(0.1 \mathrm{mM}, 180 \mu \mathrm{L})$ and $250 \mu \mathrm{M}$ ascorbic acid $(30 \mu \mathrm{L})$ served as the positive control.

\subsection{Ferrous Ion Chelating Activity}

Chelating of ferrous ions was measured by the methods of Shimada et al. [31]. Cookie extract solution $(1 \mathrm{~mL})$, methanol $(3.7 \mathrm{~mL})$, ferrozine $(5 \mathrm{mM}, 0.2 \mathrm{~mL})$, and $\mathrm{FeCl}_{2}(2 \mathrm{mM}, 0.1 \mathrm{~mL})$ were mixed and reacted at room temperature in the dark for $10 \mathrm{~min}$, and absorbance was measured at $562 \mathrm{~nm}$ spectrophotometrically using a microplate reader (Synergy HT, Bioterk instruments, Winooski, VT, USA). The ferrous ion chelating activity was calculated as

$$
\text { Ferrous ion chelating activity }(\%)=\left(1-\left(\mathrm{A}_{\text {sample }} / \mathrm{A}_{\text {blank }}\right) \times 100 \%\right.
$$

where $A_{\text {sample }}$ is the absorbance of the extracted solution with the reagent, and $A_{\text {blank }}$ is the absorbance of $100 \mu \mathrm{L}$ deionized water with the reagent. An aqueous solution of EDTA $(100 \mu \mathrm{L}, 500 \mu \mathrm{M})$ served as the positive control.

\subsection{Determination of Reducing Power}

Reducing power was determined spectrophotometrically, as above, using the ferricyanide method of Oyaizu [32]. Cookie extract solution $(1 \mathrm{~mL})$ was added to a $0.2 \mathrm{M}$ sodium phosphate buffer at $\mathrm{pH} 6.6$ $(1 \mathrm{~mL})$ with $1 \%$ potassium ferricyanide $(1 \mathrm{~mL})$. The mixture was vortexed and incubated at $50{ }^{\circ} \mathrm{C}$ for $20 \mathrm{~min}$ and then $10 \%$ trichloroacetic acid $(1 \mathrm{~mL})$ was added. The mixture was centrifuged at $1700 \times g$ at $4{ }^{\circ} \mathrm{C}$ for $10 \mathrm{~min}$, after which $1 \mathrm{~mL}$ of supernatant was diluted with distilled water $(1 \mathrm{~mL})$ and $0.1 \%$ ferric chloride $(0.2 \mathrm{~mL})$ was added. Absorbance was measured at $700 \mathrm{~nm}$. A reaction mixture containing deionized water $(125 \mu \mathrm{L})$ served as the blank, and an aqueous solution of ascorbic acid $(125 \mu \mathrm{L}, 500 \mu \mathrm{M})$ served as the positive control. A higher $\mathrm{OD}_{700}$ value indicated stronger reducing power.

\subsection{Texture Analysis}

The dark brown sugar cookies and sucrose control cookies were broken with a TA.XT2 Texture Analyzer (Stable Micro Systems Co., Ltd., Haslemere, UK) according to the methods of Tarancon et al. [33]. A $4 \mathrm{~mm}$ diameter aluminum cylindrical $\mathrm{P} / 25 \mathrm{~A}$ probe was used in the compression test. The test conditions were: supports $50 \mathrm{~mm}$ apart, a target value of $50 \%$, and a trigger load of $20 \mathrm{~g}$ at $1 \mathrm{~mm} / \mathrm{s}$ test speed. The force needed to break the cookies $(\mathrm{N})$ (breaking strength) was measured. 


\subsection{Statistical Analysis}

The data were analyzed with the SPSS statistics program for Windows version 12 (SPSS Inc., Chicago, IL, USA). ANOVA and Duncan's multiple range test were used to test differences between treatments at a $5 \%$ significance level $(p<0.05)$.

\section{Results and Discussion}

\subsection{Effects of the Addition of Dark Brown Sugar, Calcium Carbonate, Chitosan, and Chioligosaccharide on the} Formation of Acrylamide and HMF in Cookies and Their Physicochemical Properties

The addition of dark brown sugar had a significant effect on cookie diameter and thickness $(p<0.05)$ (Table 1). In general, the diameter of brown sugar cookies increased and the thickness of cookies decreased as the dark brown sugar replaced sucrose. As a result, the spread ratio of the cookies also increased, perhaps because the small particle size of the dark brown sugar caused the low-viscosity cookie dough to flow. The thinner the cookie dough, the higher the acrylamide and HMF levels generated during baking. The acrylamide and HMF contents of dark brown cookies increased after baking (Figure 1). The addition of $1 \%$ chitosan, chitooligosaccharide, or calcium carbonate did not decrease the acrylamide levels in cookies. Acar et al. made cookie dough rolled out to a thickness of 1 $\mathrm{cm}$ [10]. They reported the acrylamide content to be $128 \mathrm{ng} / \mathrm{g}$ in their control cookies, while in this study, the cookie dough was rolled out to a thickness of $0.2 \mathrm{~cm}$. The thinner cookie dough was baked at a high temperature, which increased the amount of acrylamide formed in the cookies $(1,980 \mathrm{ng} / \mathrm{g})$. Calcium carbonate, chitosan, and chitooligosaccharide could not mitigate acrylamide formation in dark brown sugar cookies at this concentration, which might be due to these cookies being slightly thinner $(p>0.05)$ than dark brown sugar cookies (Table 1). The addition of calcium carbonate significantly decreased the acrylamide formation in their cookie samples [10]. Calcium cations mitigated acrylamide formation by increasing hydroxymethylfurfural and furfural concentrations [14]. Gokmen et al. [15] reported that the Schiff base formation was mitigated and changed to another pathway, with the dehydration of glucose generating hydroxymethylfurfural and furfural [15]. The reaction proceeded in this way when calcium ions were increased. Nevertheless, the presence of calcium ions was not associated with either a reduction in acrylamide formation or an increase the amount of reducing sugar in the present study (Figure 1a and Figure 3). These results agree with the mechanistic model based on an asparagine-related pathway proposed by Nguyen et al. [34]. They claimed that fructose reacted with asparagine to form a Schiff base without any Amadori rearrangement product or sugar fragmentation before decarboxylation to produce acrylamide. The high amount of acrylamide formation in dark brown sugar cookies could not be reduced by adding $1 \%$ calcium carbonate, chitosan, and chitooligosaccharide.

The HMF content (5,439-10,123 ppm) of the brown sugar cookies was significantly higher than that of the sucrose cookies (1030 ppm) (Figure 1b), and there was more HMF than acrylamide in brown sugar cookies (Figure 1). The addition 1\% calcium carbonate, chitosan, and chitooligosaccharide did not significantly change the concentration of HMF in dark brown sugar cookies (Figure 1b). White sugar itself is free of HMF [34] and HMF levels in light and dark brown sugar are in the range of 11.9-16.4 and $12.3-23.3 \mathrm{mg} / \mathrm{kg}$, respectively [35]. The dehydration of reducing sugar via beta-elimination is central in thermally induced sugar degradation under anhydrous conditions [36]. A high HMF level can be found after thermal and/or acid-catalyzed caramelization of D-glucose at $200{ }^{\circ} \mathrm{C}$ for $2 \mathrm{~h}$ [37]. The corresponding reaction of D-fructose induces a significantly higher HMF concentration [38]. In a biscuit model [25], HMF was generated after 1,2-enolization, dehydration, and cyclization reactions from Amadori product degradation at an advanced stage of the Maillard reaction and from sugar caramelization. The addition of chitooligosaccharide may have induced HMF formation (Figure 1b), but HMF levels did not differ between brown sugar cookies baked with either high- or low-acrylamide dark brown sugar (Figure 1). This indicates that in the present study, HMF mainly came from dark brown sugar with much reducing sugar, which led to more caramelization and Maillard reaction products during baking (Figure 1). In this scenario, heating of reducing sugars and asparagines would 
generate significant amounts of HMF and the reducing sugars would react with chitooligosaccharide to form more HMF (Figure 1b). The carbonyl group of the reducing sugars fructose or glucose would react with the chitooligosaccharide amino group to form HMF and chitooligosaccharide-sugar conjugates of Maillard reaction products, and the latter would also generate HMF during the baking process. In a glucose-asparagine solution [14], the addition of calcium ions prior to thermal processing induced the formation of furfural and HMF and reduced acrylamide formation, but no correlation was found between HMF and acrylamide in the present study $(r=0.277)$. Labeling studies have shown that sucrose decomposes to release a fructofuranosyl cation and free glucose as a reactive intermediate, which can be dehydrated to release $\mathrm{H}^{+}$and HMF [39]; however, the decomposed sucrose pathway was not the main reaction generating HMF in our brown sugar cookies (Figure 1b).

Table 1. Effect of calcium carbonate, chitosan, and chitooligosaccharide on spread factor in brown sugar cookies.

\begin{tabular}{lccc}
\hline & Diameter $(\mathbf{c m})$ & Thickness $(\mathbf{c m})$ & Spread Ratio \\
\hline SC & $6.09 \pm 0.07^{\mathrm{b}}$ & $0.78 \pm 0.11^{\mathrm{a}}$ & $8.02 \pm 1.05^{\mathrm{b}}$ \\
HC & $6.63 \pm 0.08^{\mathrm{a}}$ & $0.56 \pm 0.04^{\mathrm{b}}$ & $12.12 \pm 0.84^{\mathrm{a}}$ \\
HCa & $6.54 \pm 0.05^{\mathrm{a}}$ & $0.52 \pm 0.04^{\mathrm{b}}$ & $12.72 \pm 0.88^{\mathrm{a}}$ \\
HCh & $6.53 \pm 0.03^{\mathrm{a}}$ & $0.53 \pm 0.03^{\mathrm{b}}$ & $12.52 \pm 0.74^{\mathrm{a}}$ \\
HCho & $6.62 \pm 0.13^{\mathrm{a}}$ & $0.51 \pm 0.03^{\mathrm{b}}$ & $13.28 \pm 1.19^{\mathrm{a}}$ \\
LC & $6.61 \pm 0.11^{\mathrm{a}}$ & $0.57 \pm 0.07^{\mathrm{b}}$ & $11.83 \pm 1.46^{\mathrm{a}}$ \\
LCa & $6.58 \pm 0.13^{\mathrm{a}}$ & $0.51 \pm 0.03^{\mathrm{b}}$ & $13.14 \pm 0.56^{\mathrm{a}}$ \\
LCh & $6.57 \pm 0.07^{\mathrm{a}}$ & $0.57 \pm 0.06^{\mathrm{b}}$ & $11.62 \pm 1.29^{\mathrm{a}}$ \\
LCho & $6.59 \pm 0.03^{\mathrm{a}}$ & $0.49 \pm 0.03^{\mathrm{b}}$ & $13.54 \pm 0.68^{\mathrm{a}}$ \\
\hline
\end{tabular}

Expressed as mean \pm standard deviation $(n=3)$. Values followed by different letters within each column are significantly different from each other $(p<0.05)$. SC: Sucrose cookie; HC: High-acrylamide brown sugar cookie; HCa: HC + calcium carbonate; HCh: HC + chitosan; HCho: HC + chitooligosaccharide; LC: Low-acrylamide brown sugar cookie; LCa: LC + calcium carbonate; LCh: LC + chitosan; LCho: LC + chitooligosaccharide.

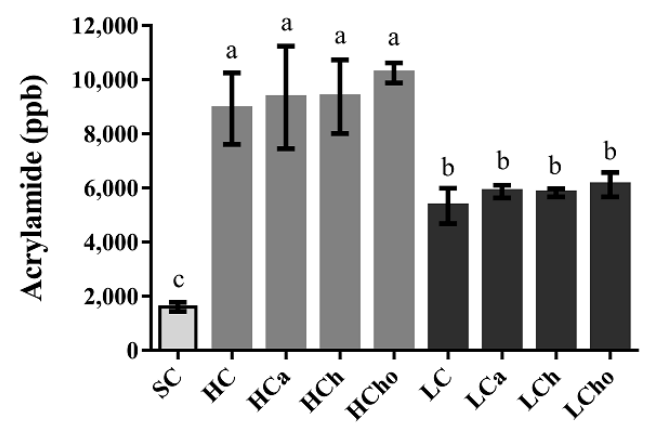

(a)

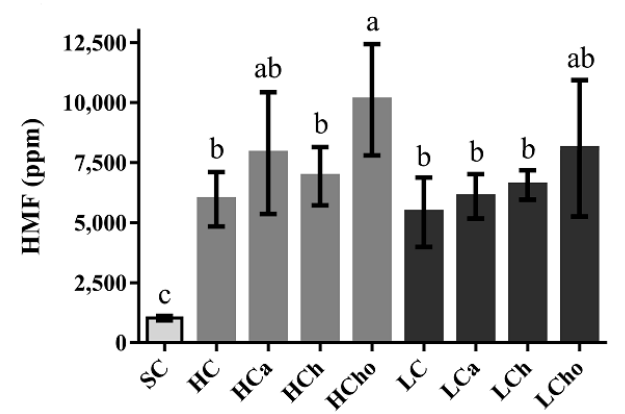

(b)

Figure 1. Effect of calcium carbonate, chitosan, and chitooligosaccharide on acrylamide (a) and hydroxymethylfurfural (HMF) (b) formation in brown sugar cookies. ${ }^{\text {a-c }}$ Indicate significant difference between different groups ( $n=3 ; p<0.05)$. SC: Sucrose cookie; HC: High acrylamide level of brown sugar in cookie; HCa: HC + calcium carbonate; HCh: HC + chitosan; HCho: HC + chitooligosaccharide; LC: Low acrylamide level of brown sugar in cookie; LCa: LC + calcium carbonate; LCh: LC + chitosan; LCho: LC + chitooligosaccharide. 
The $\mathrm{pH}$ values of the cookie ingredients sucrose, dark brown sugar with high acrylamide (908 ppb), dark brown sugar with low acrylamide (140 ppb), calcium carbonate, chitosan, and chitooligosaccharide were $5.83,5.77,6.21,9.75,3.62$, and 6.26 , respectively. Addition of $1 \%$ chitosan or chitooligosaccharide to brown sugar cookie mixes significantly decreased the $\mathrm{pH}(p<0.05)$ in both the cookie dough and baked cookies compared with the sucrose controls (Figure 2). Addition of $1 \%$ calcium carbonate had no effect on the $\mathrm{pH}$ of either experimental or control cookie dough. We explain these results as follows. Amino groups of proteins or chitosans reacted with a carbonyl source in the reducing sugar and initiated the Maillard reaction during baking, resulting in the removal of water. Hydrogen ions were generated by the Amadori rearrangement, thus decreasing the $\mathrm{pH}$ of cookies (Figure $2 \mathrm{~b}$ ).
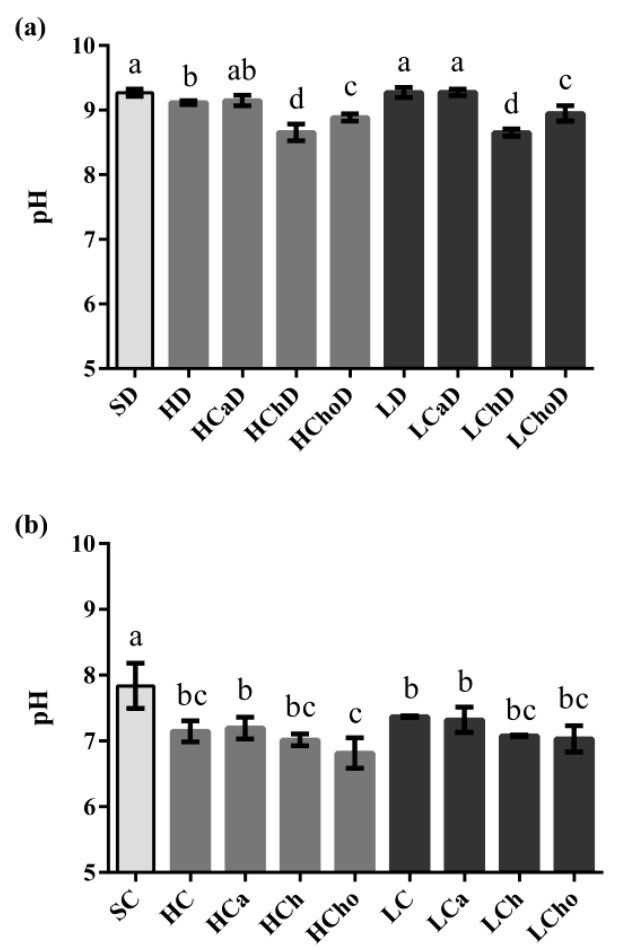

Figure 2. Effect of calcium carbonate, chitosan, and chitooligosaccharide on the $\mathrm{pH}$ in brown sugar cookie dough (a) and cookies (b). ${ }^{\text {a-d }}$ Indicate significant difference between different groups ( $\mathrm{n}=3$; $p<0.05)$. SD: Sucrose dough; HD: High acrylamide level of brown sugar in dough; HCaD: HD + calcium carbonate; HChD: HD + chitosan; HChoD: HD + chitooligosaccharide; LD: Low acrylamide level of brown sugar in dough; LCaD: LD + calcium carbonate; LChD: LD + chitosan; LChoD: LD + chitooligosaccharide; SC: Sucrose cookie; HC: High acrylamide level of brown sugar in cookie; HCa: HC + calcium carbonate; HCh: HC + chitosan; HCho: HC + chitooligosaccharide; LC: Low acrylamide level of brown sugar in cookie; LCa: LC + calcium carbonate; LCh: LC + chitosan; LCho: LC + chitooligosaccharide.

Other researchers have reported similar findings. Clawson and Taylor [40] claimed that the $\mathrm{pH}$ of milled wheat heated in sealed glass ampoules at $121^{\circ} \mathrm{C}$ for $70 \mathrm{~min}$ decreased from an initial value of 6.12 to 5.88 and from 7.81 to 6.32 [40]. Hamlet and Sadd [41] also found that the pH decreased from 5.91 to 4.73 in a pressure-cooker in which water, salt, and basic flour dough chips were cooked for $20 \mathrm{~min}$ at $180^{\circ} \mathrm{C}$. Divalent calcium ions have also been shown to induce a $\mathrm{pH}$ decrease in paste, mitigating the formation of acrylamide [42], possibly due to the removal of protons from sulfur atoms, ionizable oxygen, or nitrogen, which share electrons with hydrogen atoms. When the $\mathrm{pH}$ is not very high, most protons would be removed prior to the addition of calcium ions; when the $\mathrm{pH}$ is high enough, competition would occur between calcium ions and protons [43]. Despite these expectations, the addition of a mere $1 \%$ calcium carbonate had no effect on the $\mathrm{pH}$ of the brown sugar cookie paste and cookies in the present study (Figure 2). 


\subsection{Reducing Sugar in Brown Sugar Dough and Cookies}

No reducing sugars were detected in the sucrose. However, experiments showed that dark brown sugar contained acrylamide levels ranging from 30.17 to $70.17 \mu \mathrm{g} / \mathrm{mL}$. Brown sugar basically consists of fructose, glucose, and sucrose [44]. We also found that adding dark brown sugar with a high level of acrylamide combined with chitosan or chitooligosaccharide could significantly increase the amount of reducing sugar in the cookie dough (Figure 3a). This is because the acetyl groups of the chitosan and chitooligosaccharide will react with dinitrosalicylic acid, thereby increasing the spectrophotometric absorbance recorded during reducing sugar assays [45]. However, the reducing sugar content of baked cookies in the present study was no different between the test mixes and controls, all of which ranged between 611.6 and $673.8 \mu \mathrm{g} / \mathrm{mL}$ (Figure 3b). Gokmen and Senyuva [14] claimed that when the level of calcium cations was increased, the amount of reducing sugar and glucose decreased in a glucose-asparagine model solution. No significant decrease in the concentration of reducing sugar in brown sugar cookies fortified with $1 \%$ calcium carbonate was reported in this study, showing that this is not the case with real food. Calcium influences the rate of decomposition of reaction precursors [14], and the presence of calcium in the brown sugar cookie test mixes no doubt influenced both the characteristics and type of the products during baking.

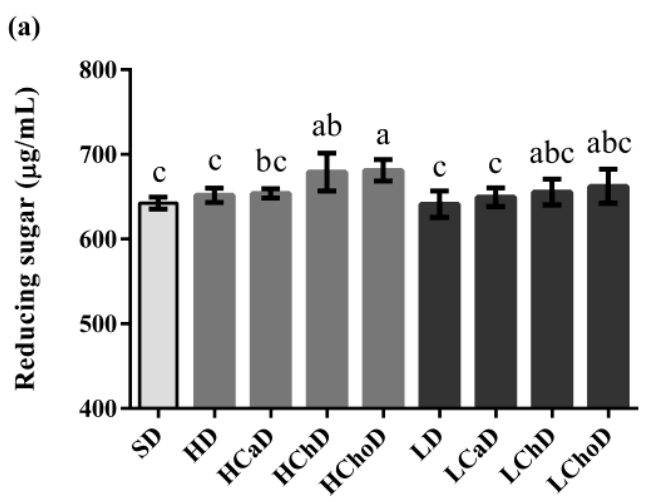

(b)

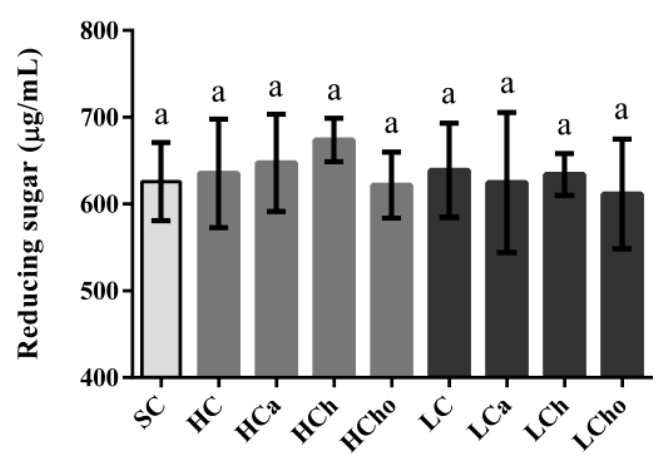

Figure 3. Effect of calcium carbonate, chitosan, and chitooligosaccharide on reducing sugar concentration in brown sugar cookie dough (a) and cookies (b). ${ }^{a-c}$ Indicate significant difference between different groups ( $\mathrm{n}=3 ; p<0.05)$. SD: Sucrose dough; HD: High acrylamide level of brown sugar in dough; HCaD: HD + calcium carbonate; HChD: HD + chitosan; HChoD: HD + chitooligosaccharide; LD: Low acrylamide level of brown sugar in dough; LCaD: LD + calcium carbonate; LChD: LD + chitosan; LChoD: LD + chitooligosaccharide; SC: Sucrose cookie; HC: High acrylamide level of brown sugar in cookie; $\mathrm{HCa}$ : $\mathrm{HC}+$ calcium carbonate; $\mathrm{HCh}$ : $\mathrm{HC}+$ chitosan; $\mathrm{HCho:} \mathrm{HC}+$ chitooligosaccharide; LC: Low acrylamide level of brown sugar in cookie; LCa: LC + calcium carbonate; LCh: LC + chitosan; LCho: LC + chitooligosaccharide.

As can be seen in Figure 4, the color and appearance of the cookies were strongly affected by the presence of dark brown sugar and chitooligosaccharide, which decreased the $L$ and $b$ values of the 
cookies (Table 2). The greater cookie spread of brown sugar cookies was also associated with a decrease in the $\mathrm{L}$ and $\mathrm{b}$ values of the cookies compared with sucrose control cookies (Table 2). Acrylamide formation demonstrated a negative correlation with the $\mathrm{L}$ value of the cookies $(\mathrm{r}=-0.739)$.
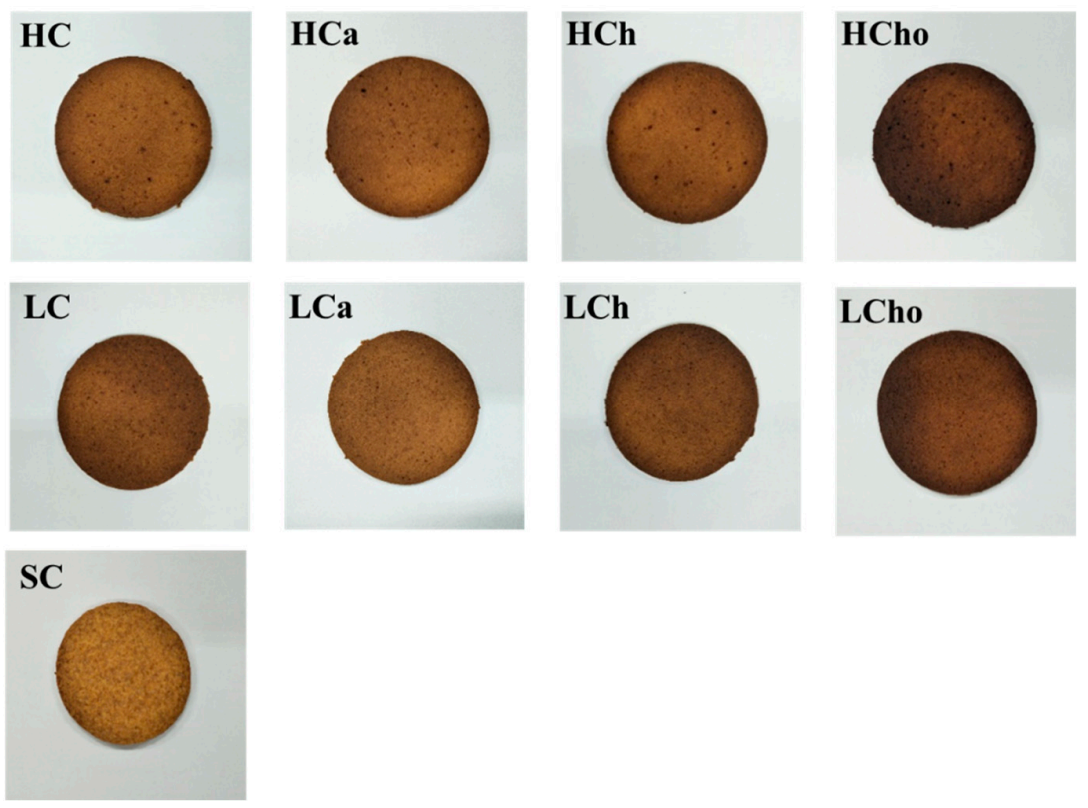

Figure 4. Effect of calcium carbonate, chitosan, and chitooligosaccharide on appearance in brown sugar cookies. SC: Sucrose cookie; HC: High acrylamide level of brown sugar in cookie; HCa: HC + calcium carbonate; HCh: HC + chitosan; HCho: HC + chitooligosaccharide; LC: Low acrylamide level of brown sugar in cookie; LCa: LC + calcium carbonate; LCh: LC + chitosan; LCho: LC + chitooligosaccharide.

Table 2. Effect of calcium carbonate, chitosan, and chitooligosaccharide on the color values in brown sugar cookies.

\begin{tabular}{lccccc}
\hline & $\mathbf{L}$ & $\mathbf{a}$ & $\mathbf{b}$ & $\Delta \mathbf{E}$ & BI \\
\hline SC & $62.80 \pm 4.00^{\mathrm{a}}$ & $4.3 \pm 0.61^{\mathrm{f}}$ & $33.6 \pm 2.17^{\mathrm{a}}$ & - & 78.42 \\
HBC & $42.30 \pm 1.26^{\mathrm{d}}$ & $7.0 \pm 0.27^{\mathrm{ab}}$ & $23.3 \pm 0.82^{\mathrm{cd}}$ & - & 89.06 \\
HBCa & $42.30 \pm 0.87^{\mathrm{d}}$ & $7.1 \pm 0.31^{\mathrm{a}}$ & $23.2 \pm 0.62^{\mathrm{cd}}$ & 0.14 & 88.78 \\
HBCh & $42.90 \pm 0.75^{\mathrm{cd}}$ & $6.9 \pm 0.05^{\mathrm{abc}}$ & $23.6 \pm 0.58^{\mathrm{cd}}$ & 0.68 & 88.57 \\
HBCho & $31.50 \pm 2.77^{\mathrm{f}}$ & $6.2 \pm 0.68^{\mathrm{de}}$ & $16.5 \pm 1.95^{\mathrm{f}}$ & 12.79 & 86.21 \\
LBC & $47.50 \pm 3.83^{\mathrm{b}}$ & $6.5 \pm 0.45^{\mathrm{cd}}$ & $26.1 \pm 1.95^{\mathrm{b}}$ & - & 86.60 \\
LBCa & $41.60 \pm 3.47^{\mathrm{d}}$ & $6.7 \pm 0.27^{\mathrm{bc}}$ & $22.8 \pm 2.03^{\mathrm{d}}$ & 6.76 & 88.18 \\
LBCh & $44.10 \pm 3.00^{\mathrm{c}}$ & $6.2 \pm 0.17^{\mathrm{de}}$ & $24.1 \pm 1.84^{\mathrm{c}}$ & 3.96 & 86.30 \\
LBCho & $33.20 \pm 1.93^{\mathrm{e}}$ & $6.1 \pm 0.29^{\mathrm{e}}$ & $17.4 \pm 1.09^{\mathrm{e}}$ & 16.74 & 85.28 \\
\hline
\end{tabular}

Expressed as mean \pm standard deviation $(n=3)$. Values followed by different letters within each column are significantly different $(p<0.05)$. SC: Sucrose cookie; HC: High-acrylamide brown sugar cookie; HCa: HC + calcium carbonate; HCh: HC + chitosan; HCho: HC + chitooligosaccharide; LC: Low-acrylamide brown sugar cookie; LCa: LC + calcium carbonate; LCh: LC + chitosan; LCho: LC + chitooligosaccharide.

\subsection{Radical-Scavenging Activity of Brown Sugar Cookies}

An increase in DPPH-scavenging activity in brown sugar cookies was observed (Figure 5a). Brown sugar may display antioxidant properties arising from polyphenols and Maillard reaction products [46]. Yen et al. [47] reported that chitosan from shiitake mushroom stems and crab shells is not an effective scavenger for the DPPH radical. However, the DPPH radical-scavenging activity of brown sugar cookies with either high or low acrylamide content and $1 \%$ chitosan was higher $(p>0.05)$ than that of control sucrose cookies (Figure 5a). Chitosan with a high degree of deacetylation indicated high radical-scavenging effects [48] and low-molecular-weight chitosan also exhibited strong DPPH-scavenging activity [49]. The DPPH radical-scavenging activity of brown sugar cookies with $1 \%$ chitooligosaccharide was higher than that of cookies with 1\% chitosan (Figure 5a). 
Cookies made with dark brown sugar displayed higher $(p<0.05)$ reducing power than control sucrose cookies (Figure $5 b)$ and less ferrous ion chelating efficacy $(p>0.05)$. The ferrous ion chelating efficacy was lowest $(p<0.05)$ for brown sugar cookies with $1 \%$ chitooligosaccharide (Figure $5 c$ ). This may be due to the high degree of deacetylation $(90.8 \%)$ of the chitooligosaccharide, which could have reduced its ferrous ion chelating activity compared with chitosan with $85 \%$ deacetylation degrees.

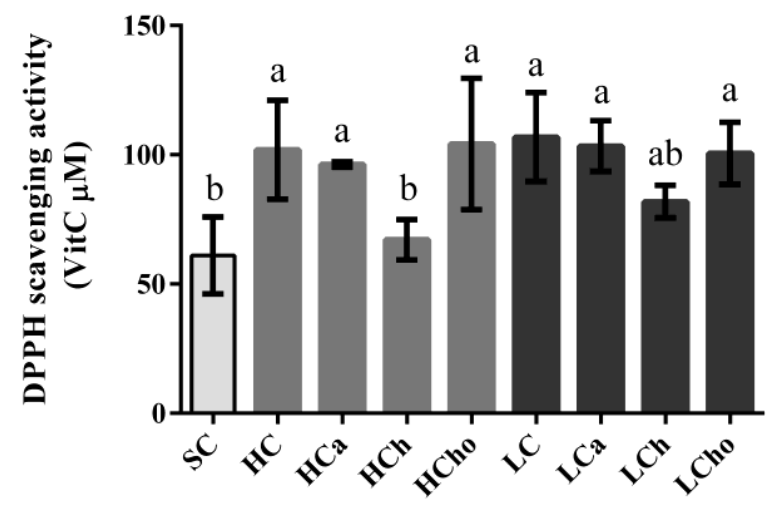

(a)

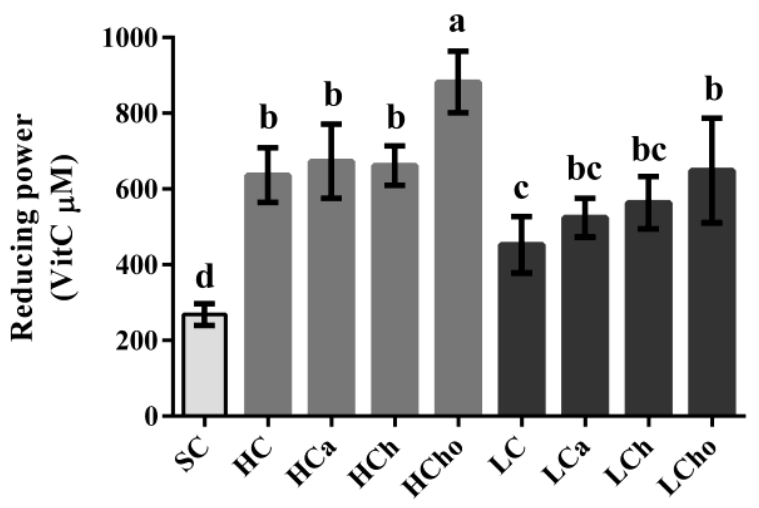

(b)

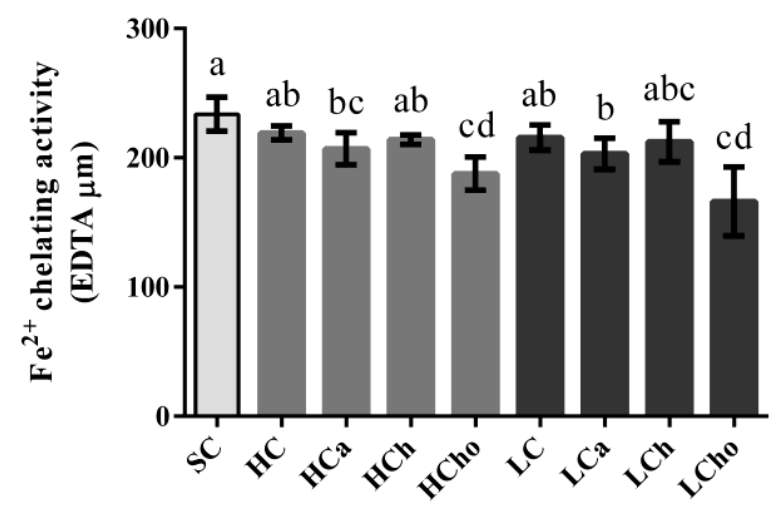

(c)

Figure 5. Effect of calcium carbonate, chitosan, and chitooligosaccharide on 1,1-diphenyl-2picrylhydrazyl hydrate (DPPH) radical-scavenging activity (a), reducing power $(\mathbf{b})$, and $\mathrm{Fe}^{2+}$ chelating activity (c) in brown sugar cookies. ${ }^{\text {a-d }}$ Indicate significant difference between different groups $(\mathrm{n}=3$; $p<0.05)$. SC: Sucrose cookie; HC: High acrylamide level of brown sugar in cookie; HCa: HC + calcium carbonate; HCh: HC + chitosan; HCho: HC + chitooligosaccharide; LC: Low acrylamide level of brown sugar in cookie; LCa: LC + calcium carbonate; LCh: LC + chitosan; LCho: LC + chitooligosaccharide. 


\subsection{Texture Analysis of Cookies}

The sucrose control cookies were harder and thicker than the brown sugar cookies, which is likely the effect of the stronger binding strength associated with a better gluten network. Figure 6 and Table 1 show that replacement of sucrose with dark brown sugar led to a decrease in cookie hardness and thickness. No significant difference in hardness was found with the addition of calcium carbonate, chitosan, or chitooligosaccharide (Figure 6).

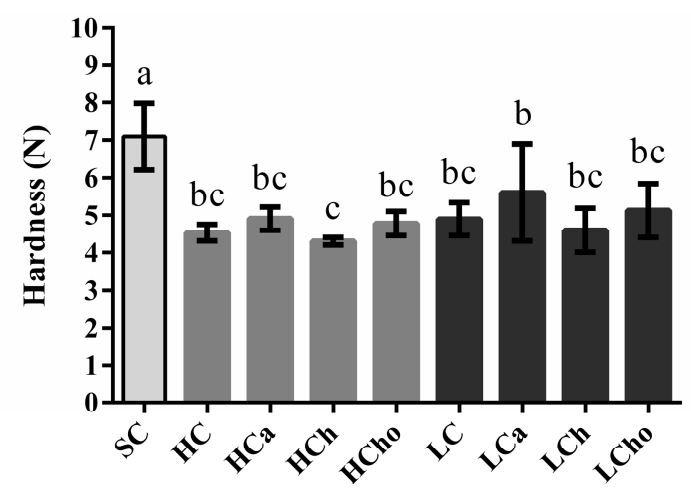

Figure 6. Effect of calcium carbonate, chitosan, and chitooligosaccharide on hardness in brown sugar cookies. ${ }^{a-c}$ Indicate significant difference between different groups $(n=3 ; p<0.05)$. SC: Sucrose cookie; HC: High acrylamide level of brown sugar in cookie; HCa: HC + calcium carbonate; HCh: HC + chitosan; HCho: HC + chitooligosaccharide; LC: Low acrylamide level of brown sugar in cookie; LCa: LC + calcium carbonate; LCh: LC + chitosan; LCho: LC + chitooligosaccharide.

\section{Conclusions}

Sucrose addition in cookie making generated less reducing power, acrylamide, and HMF and formed a thicker and harder cookie which was lighter in appearance compared with cookies made with dark brown sugar. Acrylamide levels in brown sugar cookies made with dark brown sugar containing a high concentration of acrylamide were higher than those in cookies made with dark brown sugar containing a low concentration of acrylamide. The $\mathrm{pH}$ of sucrose control cookies was higher than that of dark brown sugar cookies, and the HMF content in the cookies was not influenced by the acrylamide levels of the dark brown sugar. Calcium carbonate, chitosan, and chitooligosaccharide could not mitigate acrylamide and HMF formation in brown sugar cookies at a concentration of $1 \%$. The addition of $1 \%$ chitooligosaccharide increased the HMF content of the cookies, and the cookies with added chitooligosaccharide appeared more charred. The addition of chitooligosaccharide apparently intensified both the Maillard reaction and caramelization in the cookie dough when baked. In order to accommodate consumer groups who like the brown sugar flavor, cookie manufacturers and the baking industry in general should choose sucrose or brown sugar with a lower acrylamide content as a raw material to prevent the final product from containing too much acrylamide and HMF. They should generally avoid dark brown sugar containing high levels of acrylamide.

Author Contributions: Conceptualization, W.-C.S. and Y.-S.S.; methodology, W.-C.S., Y.-S.S., and H.-I.H.; formal analysis, J.-Y.F.; investigation, H.-I.H. and J.-Y.F.; resources, Y.-S.S. and J.-Y.F.

Funding: This research was funded by the National Taiwan Ocean University and University System of Taipei (USTP-NTOU-TMU-108-03).

Acknowledgments: The authors are grateful for the funding provided by the National Taiwan Ocean University and University System of Taipei and the edition of this manuscript by Mark J. Grygier, Center of Excellence for the Oceans at National Taiwan Ocean University.

Conflicts of Interest: The authors declare no conflict of interests. 


\section{References}

1. Asikin, Y.; Hirose, N.; Tamaki, H.; Ito, S.; Oku, H. Effects of different drying-solidification processes on physical properties, volatile fraction, and antioxidant activity of non-centrifugal cane brown sugar. LWT-Food Sci. Technol. 2016, 66, 340-347. [CrossRef]

2. Centre for Food Safety. Acrylamide in Dark Brown Sugar. Food Safety Focus 2015 Food Incident Highlight. Available online: https://www.cfs.gov.hk/english/multimedia/multimedia_pub/multimedia_pub_fsf_111_03. html (accessed on 29 May 2019).

3. Ducat, G.; Felsner, M.L.; Da Costa Neto, P.R.; Quinaia, S.P. Development and in house validation of a new thermogravimetric method for water content analysis in soft brown sugar. Food Chem. 2015, 177, 158-164. [CrossRef] [PubMed]

4. Asikin, Y.; Kamiya, A.; Mizu, M.; Takara, K.; Tamaki, H.; Wada, K. Changes in the physicochemical characteristics including flavor components and Maillard reaction products of non-centrifugal cane brown sugar during storage. Food Chem. 2014, 149, 170-177. [CrossRef] [PubMed]

5. Lineback, D.R.; Coughlin, J.R.; Stadler, R.H. Acrylamide in foods: A review of the science and future considerations. Annu. Rev. Food Sci. Technol. 2012, 3, 15-35. [CrossRef] [PubMed]

6. Tareke, E.; Rydberg, P.; Karlsson, P.; Eriksson, S.; Tornqvist, M. Acrylamide: A cooking carcinogen? Chem. Res. Toxicol. 2000, 13, 517-522. [CrossRef] [PubMed]

7. Surh, Y.J.; Tannenbaum, S.R. Activation of the Maillard reaction product 5-(hydroxmethyl)furfural to strong mutagens via allylic sulfonation and chlorination. Chem. Res. Toxicol. 1994, 7, 313-318. [CrossRef] [PubMed]

8. Quarta, B.; Anese, M. The effect of salts on acrylamide and 5-hydroxymethylfurfural formation in glucose-asparagine model solutions and biscuits. J. Food Nutr. Res. 2010, 49, 69-77.

9. Cheng, W.C.; Kao, Y.M.; Shih, D.Y.C.; Chou, S.S.; Yeh, A.I. Validation of an improved LC/MS/MS method for acrylamide analysis in food. J. Food Drug Anal. 2009, 17, 190-197.

10. Acar, O.C.; Pollio, M.; Di Monaco, R.; Fogliano, V.; Gokmen, V. Effect of calcium on acrylamide level and sensory properties of cookies. Food Bioprocess Technol. 2012, 5, 519-526. [CrossRef]

11. Chang, Y.W.; Sung, W.C.; Chen, J.Y. Effect of different molecular weight chitosans on the mitigation of acrylamide formation and the functional properties of the resultant Maillard reaction products. Food Chem. 2016, 199, 581-589. [CrossRef]

12. Sung, W.C.; Chang, Y.W.; Chou, Y.H.; Hsiao, H.I. The functional properties of chitosan-glucose-asparagine Maillard reaction products and mitigation of acrylamide formation by chitosans. Food Chem. 2018, 243, 141-144. [CrossRef] [PubMed]

13. Lindsay, R.C.; Jang, S. Chemical intervention strategies for substantial suppression of acrylamide formation in fried potato products. Adv. Exp. Med. Biol. 2005, 561, 393-404. [CrossRef] [PubMed]

14. Gokmen, V.; Senyuva, H.Z. Acrylamide formation is prevented by diavalent cations during the Maillard reaction. Food Chem. 2007, 103, 196-203. [CrossRef]

15. Gokmen, V.; Acar, O.C.; Koksel, H.; Acar, J. Effects of dough formula and baking conditions on acrylamide and hydroxymethylfurfural formation in cookies. Food Chem. 2007, 104, 1136-1142. [CrossRef]

16. Gokmen, V.; Akbudak, B.; Serpen, A.; Acar, J.; Turan, Z.M.; Eris, A. Effects of controlled atmosphere storage and low-dose irradiation on potato tuber components affecting acrylamide and color formations upon frying. Eur. Food Res. Technol. 2007, 224, 681-687. [CrossRef]

17. Amrein, T.M.; Schonbachler, B.; Escher, F.; Amado, R. Acrylamide in gingerbread: Critical factors for formation and possible ways for reduction. J. Agric. Food Chem. 2004, 52, 4282-4288. [CrossRef] [PubMed]

18. Biedermann, M.; Grob, K. Model studies on acrylamide formation in potato, wheat flour and corn starch; ways to reduce acrylamide contents in bakery ware. Mitt. Lebensm. Hyg. 2003, 94, 406-422.

19. Jung, M.Y.; Choi, D.S.; Ju, J.W. A novel technique for limitation of acrylamide formation in fried and baked corn chips and in French fries. J. Food Sci. 2003, 68, 1287-1290. [CrossRef]

20. Brathen, E.; Kita, A.; Knutsen, S.H.; Wicklund, T. Addition of glycine reduces the content of acrylamide in cereal and potato products. J. Agric. Food Chem. 2005, 53, 3259-3264. [CrossRef]

21. Pedreschi, F.; Kaack, K.; Granby, K. The effect of asparaginase on acrylamide formation in French fries. Food Chem. 2008, 109, 386-392. [CrossRef]

22. Ciesarova, Z.; Kiss, E.; Boegl, P. Impact of L-asparaginase on acrylamide content in potato products. J. Food Nutr. Res. 2006, 45, 141-146. 
23. AACC. Approved Methods of the American Association of Cereal Chemists, 10th ed.; AACC: Saint Paul, MN, USA, 2000.

24. Hwang, H.S.; Singh, M.; Lee, S. Properties of cookies made with natural wax-vegetable oil organogels. J. Food Sci. 2016, 81, 1045-1054. [CrossRef] [PubMed]

25. Navarro, M.; Morales, F.J. Effect of hydroxytyrosol and olive leaf extract on 1, 2-dicarbonyl compounds, hydroxymethylfurfural and advanced glycation end products in a biscuit model. Food Chem. 2017, 217, 602-609. [CrossRef] [PubMed]

26. James, C.S. Analytical Chemistry of Foods; Chapman and Hall: New York, NY, USA, 1995.

27. Dinç, S.; Javidipour, I.; Özbas, Ö.; Tekin, A. Utilization of zero-trans non-interesterified and interesterified shortenings in cookie production. J. Food Sci. Technol. 2014, 51, 365-370. [CrossRef] [PubMed]

28. Barber, D.S.; Hunt, J.R.; Ehrich, M.F.; Lehning, E.J.; LoPachin, R.M. Metabolism, toxicokinetics and hemoglobin adduct formation in rats following subacute and subchronic acrylamide dosing. Neurotoxicology 2001, 22, 341-353. [CrossRef]

29. Oral, R.A.; Mortas, M.; Dogan, M.; Sarioglu, K.; Yazici, F. New approaches to determination of HMF. Food Chem. 2014, 143, 367-370. [CrossRef] [PubMed]

30. Kim, M.K.; Lee, J.M.; Do, J.S.; Bang, W.S. Antioxidant activities and quality characteristics of omija (Schizandra chinesis Baillon) cookies. Food Sci. Biotechnol. 2015, 24, 931-937. [CrossRef]

31. Shimada, K.; Fujikawa, K.; Yahara, K.; Nakamura, T. Antioxidative properties of xanthan on the antioxidation of soybean oil in cyclodextrin emulsion. J. Agric. Food Chem. 1992, 40, 945-948. [CrossRef]

32. Oyaizu, M. Antioxidative activities of browning products of glucosamine fractionated by organic solvent and thin-layer chromatography. Nippon Shokuhin Kogyo Gakkaishi 1988, 35, 771-775. [CrossRef]

33. Tarancón, P.; Salvador, A.; Sanz, T. Sunflower oil-water-cellulose ether emulsions as trans-fatty acid-free fat replacers in biscuits: Texture and acceptability study. Food Bioprocess Technol. 2013, 6, 2389-2398. [CrossRef]

34. Nguyen, H.T.; van der Fels-Klerx, H.J.I.; van Boekel, M.A.J.S. Acrylamide and 5-hydroxymethylfurfural formation during biscuit baking. Part II: Effect of the ratio of reducing sugars and asparagines. Food Chem. 2017, 230, 14-23. [CrossRef] [PubMed]

35. Polovková, M.; Šimko, P. Determination and occurrence of 5-hydroxymethyl-2-furaldehyde in white and brown sugar by high performance liquid chromatography. Food Control. 2017, 78, 183-186. [CrossRef]

36. Risner, C.H.; Kiser, M.J.; Dube, M.F. An Aqueous High-Performance Liquid Chromatographic Procedure for the Determination of 5-Hydroxymethylfurfural in Honey and Other Sugar-containing Materials. J. Food Sci. 2006, 71, 179-184. [CrossRef]

37. Kroh, L.W. Caramelisation in food and beverages. Food Chem. 1994, 51, 373-379. [CrossRef]

38. Telegdy Kovats, L.; Orsi, F. Some observations on caramelisation. Period. Polytech. 1973, 17, 373-385.

39. Locas, C.P.; Yaylayan, V.A. Isotope labeling studies on the formation of 5-(hydroxymethyl)-2-furaldehyde (HMF) from sucrose by pyrolysis-GC/MS. J. Agric. Food Chem. 2008, 56, 6717-6723. [CrossRef] [PubMed]

40. Clawson, A.R.; Taylor, A.J. Chemical changes during cooking of wheat. Food Chem. 1993, 47, $337-343$. [CrossRef]

41. Hamlet, C.G.; Sadd, P.A. Effects of yeast stress and pH on 3-monchloropropanediol (3-MCPD)-producing reactions in model dough systems. Food Addit. Contam. 2005, 22, 616-623. [CrossRef]

42. Levin, R.A.; Ryan, S.M. Determining the effect of calcium cations on acrylamide formation in cooked wheat products using a model system. J. Agric. Food Chem. 2009, 57, 6823-6829. [CrossRef]

43. Clydesdale, F.M. Minerals: Their chemistry and fate in food. In Trace Minerals in Food; Smith, K., Ed.; Marcel Dekker: New York, NY, USA, 1988; pp. 57-94.

44. Dos Santos, J.M.; Quináia, S.P.; Felsner, M.L. Fast and direct analysis of $\mathrm{Cr}$, $\mathrm{Cd}$ and Pb in brown sugar by GF AAS. Food Chem. 2018, 260, 19-26. [CrossRef]

45. Doolittle, R.F.; Falter, H.; Horn, M.J.; Kannan, K.K.; Mross, G.A.; Laursen, R.A.; Needleman, S.B.; Nieboer, E.; Reichlin, M. Advanced Methods in Protein Sequence Determination; Springer Science \& Business Media: New York, NY, USA, 2012; Volume 25.

46. Payet, B.; Shum Cheong Sing, A.; Smadja, J. Assessment of antioxidant activity of cane brown sugars by ABTS and DPPH radical scavenging assays: Determination of their polyphenolic and volatile constitutents. J. Agric. Food Chem. 2005, 53, 10074-10079. [CrossRef] [PubMed]

47. Yen, M.T.; Yang, J.H.; Mau, J.L. Antoxidant properties of chitosan from crab shells. Carbohydr. Polym. 2008, 74, 840-844. [CrossRef] 
48. Park, P.J.; Je, J.Y.; Kim, S.K. Free radical scavenging activities of differently deacetylated chitosans using an ESR spectrometer. Carbohydr. Polym. 2004, 55, 17-22. [CrossRef]

49. Chien, P.J.; Sheu, F.; Huang, W.T.; Su, M.S. Effect of molecular weight of chitosans on their antioxidatie activities in apple juice. Food Chem. 2007, 102, 1192-1198. [CrossRef]

(C) 2019 by the authors. Licensee MDPI, Basel, Switzerland. This article is an open access article distributed under the terms and conditions of the Creative Commons Attribution (CC BY) license (http://creativecommons.org/licenses/by/4.0/). 